\title{
PENGARUH INHALASI AROMATERAPI LAVENDER TERHADAP KECEMASAN DAN NYERI ANAK SEKOLAH
} SAAT DILAKUKAN IMUNISASI

The Effect of Aromatherapy Lavender Inhalation On Anxiety and Pain in Age School Children During Immunization

\author{
Komang Yogi Triana, Made Pande Lilik Lestari, I Nyoman Pande Suyasa \\ Program Studi Profesi Ners, STIKES Bina Usada Bali \\ *yogitriana25@gmail.coM/ 085792007055
}

\begin{abstract}
Introduction: Pain and anxiety are responses that are often shown by children who will receive immunization in the form of injections at school when School Children Immunization Month (BIAS) arrives. Pain caused by the invasive procedure can cause trauma to the child against immunization and show an uncooperative attitude. Purpose: The purpose of this study was to determine the difference in the effect of lavender aromatherapy with routine intervention on anxiety and pain in primary school children who received TD immunization. Methods: This study used a quasiexperimental design with a non-equivalent control group design post-test only. A total of 29 respondents were involved in this study who were selected by purposive sampling technique according to the inclusion criteria which were divided into 2 groups. The research instruments in this study was using Visual Analog Scale for Pain and Anxiety (VAS-P and VAS-A). Results: The results of data analysis using the Mann Whitney test showed that lavender aromatherapy was effective in reducing children's pain when immunized ( $p$ value $=0.005$ ) but did not show a significant effect on children's anxiety ( $p$ value $=0.122$ ). Conclusion: Lavender aromatherapy can be an easy and affordable distraction technique that nurses can apply when immunizing at school so that it can help control the pain felt by children.
\end{abstract}

Keywords : Anxiety, Aromatherapy, Children, Immunization, Pain.

\section{ABSTRAK}

Pendahuluan: Nyeri dan kecemasan merupakan respon yang sering ditunjukkan oleh anak-anak yang akan mendapatkan imunisasi berupa injeksi di sekolah pada saat Bulan Imunisasi Anak Sekolah (BIAS) tiba. Nyeri yang ditimbulkan oleh tindakan invasif dapat menyebabkan timbulnya trauma pada anak terhadap tindakan imunisasi dan menunjukkan sikap yang tidak kooperatif. Tujuan: Adapun tujuan dari penelitian ini adalah untuk mengetahui perbedaan pengaruh dari aromaterapi lavender dengan intervensi rutin yang diberikan terhadap kecemasan dan nyeri anak sekolah dasar yang mendapatkan imunisasi TD. Metode: Penelitian ini menggunakan desain quasi experimental dengan non-equivalent with control group design post-test only. Sebanyak 29 responden dilibatkan dalam penelitian ini yang dipilih dengan teknik purposive sampling sesuai dengan kriteria inklusi yang terbagi menjadi 2 kelompok. Instrumen penelitian ini menggunakan Visual Analog Scale (VAS) for Pain and Anxiety untuk mengukur skala nyeri dan kecemasan anak. Hasil: Hasil analisis data dengan uji Mann Whitney menunjukkan bahwa aromaterapi lavender efektif menurunkan nyeri anak saat diimunisasi ( $p$ value $=0.005$ ) namun tidak menunjukkan adanya pengaruh yang signifikan terhadap kecemasan anak ( $p$ value $=0,122$ ). Kesimpulan: Aromaterapi lavender dapat menjadi salah satu pilihan teknik distraksi yang mudah dan terjangkau untuk dapat diterapkan perawat saat melakukan imunisasi ke sekolah sehingga dapat membantu mengontrol nyeri yang dirasakan anak

Kata kunci : Anak, Aromaterapi, Imunisasi, Kecemasan, Nyeri.

\section{PENDAHULUAN}

Imunisasi adalah komponen kunci dari perawatan kesehatan primer dan hak asasi manusia yang mutlak didapatkan oleh setiap orang termasuk anak-anak (World Health Organization [WHO], 2019). Imunisasi sebagai salah satu upaya preventif untuk mencegah terjadinya penyakit infeksi, justru menjadi salah satu tindakan medis yang menimbulkan rasa nyeri bagi anak-anak (Ciftci, Ozdemir, \& Aydın, 2016; Halpert, Meier, \& Naus, 2015). Nyeri didefinisikan sebagai suatu pengalaman sensorik dan emosional yang tidak menyenangkan terkait dengan kerusakan jaringan aktual atau potensial (Treede, 2018). Nyeri yang dirasakan secara akut oleh anak dapat meningkatkan risiko gangguan kecemasan dan depresi jika tidak dikontrol dengan baik, bahkan dapat berdampak pada penurunan sistem imun tubuh (Victoria \& Murphy, 2016). Salah satunya, nyeri yang dirasakan anak akibat imunisasi. Hal ini dapat menimbulkan ketakutan anak terhadap nyeri akibat tindakan medis, seperti imunisasi sehingga muncul respon cemas yang dapat berlanjut hingga dewasa serta penolakan dari anak terhadap tindakan imunisasi 
(Şahiner, Inal, \& Akbay, 2015; Stevens, \& Marvicsin, 2016). Oleh karena itu, saat ini banyak dikembangkan teknik distraksi yang dapat membantu mengurangi nyeri saat imunisasi dan kecemasan yang dirasakan anak (Şahiner, Inal, \& Akbay, 2015).

Perawat anak memiliki peran yang penting dalam melakukan tindakan imunisasi pada anak yang langsung kontak dengan anak-anak. Prosedur yang harus diterapkan oleh perawat dimulai sejak pengkajian awal dengan memastikan bahwa anak yang akan diimunisasi dalam kondisi sehat atau tidak. Selain itu, perawat anak diharapkan dapat menunjukkan kemampuannya dalam mengidentifikasi adanya kecemasan yang dirasakan anak maupun orangtua saat tindakan imunisasi. Selanjutnya perawat sebaiknya dapat menerapkan teknik distraksi atau relaksasi yang tepat untuk mengurangi kecemasan anak maupun orangtua, termasuk teknik untuk mengontrol nyeri yang dirasakan anak nantinya (Stevens, \& Marvicsin, 2016).

Pengendalian dan penatalaksanaan nyeri adalah aspek terpenting dari kebutuhan dasar, hak asasi manusia, dan asuhan keperawatan pada anak. Nyeri dapat dikontrol dengan metode farmakologis maupun non-farmakologis termasuk dengan menerapkan terapi komplementer (Bikmoradi, Harorani, Roshanaei, Moradkhani, \& Falahinia, 2016). Penggunaan teknik farmakologi dalam mengontrol nyeri umumnya memiliki keterbatasan dan efek samping, salah satunya semprotan lidokain yang berisiko terjadi reaksi alergi penyerapan secara sistemik, bahkan distrimia jantung (Giordano, Nelson, Kohen, Nijhawan, \&. Srivastava, 2015). Oleh karena itu, pemanfaatan teknik manajemen nyeri nonfarmakologi sedang banyak dikembangkan karena tidak berisiko, murah, mudah dan aman untuk pasien termasuk anak-anak. Beberapa teknik nonfarmakologi secara komplementer yang sudah mulai diterapkan diantaranya: meditasi, yoga, relaksasi, terapi musik dan aromaterapi (Bikmoradi, Zafari, Oshvandi, Mazdeh, \&Roshanaei, 2014).

Aromaterapi menjadi salah satu pilihan yang saat ini banyak digunakan karena efeknya yang dapat menurunkan nyeri, mengurangi insomnia, mengurangi kecemasan, dan tidak membutuhkan biaya yang besar dalam penerapannya (Lakhan, Sheafer, \& Tepper, 2016). Berbagai studi mengenai aromaterapi telah banyak dilakukan, namun keefektifannya pada anak-anak masih perlu dilakukan studi lebih lanjut. Perawat disarankan untuk dapat menerapkan intervensi aromaterapi secara inhalasi karena mudah, murah, cepat dan efektif (Abbaszadeh, Tabari, Taherian, \& Torabi, (2017). Penelitian ini bertujuan untuk mengetahui pengaruh aromaterapi lavender terhadap kecemasan dan nyeri anak usia sekolah saat mendapatkan imunisasi TD.

\section{METODE \\ Desain, tempat dan waktu}

Penelitian ini dilakukan di Sekolah Dasar Negeri (SDN) 2 dan 4 Takmung, Kabupaten Klungkung, Provinsi Bali pada Bulan NovemberDesember 2019. Penelitian ini menggunakan metode quasi experimental dengan non-equivalent with control group design post-test only design (Nursalam, 2016). Data bivariat dianalsis dengan uji beda yaitu Mann Whitney Test karena data nyeri dan kecemasan tidak berdistribusi normal. Penelitian ini telah mendapatkan keterangan kelaikan etik oleh Komisi Etik Penelitian Kesehatan Bina Usada Bali dengan nomor Ethical Approval : 316/EA/KEPK-BUB-2019.

\section{Jumlah dan cara pengambilan subjek atau bahan dan alat}

Populasi dalam penelitian ini adalah seluruh siswa Sekolah Dasar (SD) kelas V di Sekolah Dasar Negeri (SDN) 2 dan 4 Takmung, Kabupaten Klungkung, Provinsi Bali. Teknik sampling yang digunakan dalam penelitian ini adalah purposive sampling, dimana sebanyak 29 siswa dilibatkan yan dibagi menjadi 2 kelompok, yaitu 15 orang dari SDN 2 sebagai kelompok intervensi dan 14 orang dari SDN 4 sebagai kelompok kontrol. Kriteria inklusi responden dalam penelitian ini antara lain: siswa kelas $V$ yang bersedia mengikuti penelitian ini dan sudah mendapatkan persetujuan dari orang tua atau wali, siswa yang mendapatkan imunisasi Td sesuai jadwal puskesmas, dan siswa yang bersedia.

Pada kelompok kontrol, peneliti beserta enumerator memberikan intervensi rutin terhadap responden selama tindakan pemberian imunisai, lalu setelah imunisasi selesai 5 menit setelahnya dilakukan pengukuran tingkat kecemasan responden dengan VAS (Visual Analog Scale)-A dan skala nyeri dengan VAS-P. Sedangkan pada kelompok intervensi pada sekolah berikutnya, peneliti dan enumerator memberikan intervensi inhalasi aromaterapi dengan cara meneteskan minyak esensial dengan aroma lavender di atas kassa sebanyak 5 tetes lalu meminta anak untuk menghirupnya dengan jarak $10 \mathrm{~cm}$ sejak 5 menit sebelum tindakan imunisasi hingga 5 menit setelah imunisasi selesai. Selanjutnya dilakukan pengukuran tingkat kecemasan subjek dengan VAS (Visual Analog Scale)-Anxiety dan skala nyeri dengan VAS-Pain.

\section{HASIL}

\section{a. Karakteristik Responden}

Karakteristik responden dalam penelitian ini dideskripsikan berdasarkan jenis datanya. Data numerik yaitu usia yang dijelaskan melalui tabel yang berisikan mean, median, dan standar deviasi. 
Sedangkan variabel kategorik yaitu jenis kelamin yang dijelaskan dalam bentuk distribusi frekuensi dan persentase.

Tabel 1. Distribusi Frekuensi Responden berdasarkan Usia dan Jenis Kelamin Tahun 2019

\begin{tabular}{lllll}
\hline Karakteristik & Mean & Median & $\begin{array}{l}\text { Min- } \\
\text { Max }\end{array}$ & Std. Deviasi \\
\hline Usia & 10,14 & 10 & $10-11$ & 0,351 \\
\hline & & & \\
\hline Karakteristik & Frekuensi & & $\begin{array}{l}\text { Persentase } \\
(\%)\end{array}$ \\
\hline Jenis & & & \\
kelamin & & & 48,3 \\
Laki-laki & 14 & & 51,7 \\
\hline Perempuan & 15 & 100 \\
\hline & 29 & & \\
\hline
\end{tabular}

Berdasarkan tabel 1 di atas dapat dilihat bahwa sebagian rata-rata responden berusia 10,14 tahun dengan usia termuda yaitu 10 tahun dan usia paling tinggi adalah 11 tahun. Responden perempuan lebih banyak dibandingkan responden laki-laki yaitu sebanyak 15 responden sedangkan laki-laki 14 responden.

b. Skala Nyeri dan Skala Kecemasan Anak Sekolah yang Mendapatkan Imunisasi TD pada Kelompok Intervensi dan Kontrol

Tabel 2. Distribusi Frekuensi Responden berdasarkan Skala Nyeri dan Skala Kecemasan Tahun 2019

\begin{tabular}{lllll}
\hline Karakteristik & Mean & Median & $\begin{array}{l}\text { Min- } \\
\text { Max }\end{array}$ & $\begin{array}{l}\text { Std. } \\
\text { Deviasi }\end{array}$
\end{tabular}

\begin{tabular}{lllll}
\hline $\begin{array}{l}\text { Kelompok } \\
\text { Intervensi }(\mathrm{n}=15)\end{array}$ & & & & \\
\hline $\begin{array}{l}\text { Skala Kecemasan } \\
\text { Skala Nyeri }\end{array}$ & 0.93 & 0 & $0-5$ & 1,58 \\
\hline $\begin{array}{l}\text { Kelompok Kontrol } \\
(\mathrm{n}=14)\end{array}$ & & & & \\
\hline Skala Kecemasan & 1,43 & 1,5 & $0-3$ & 1,38 \\
Skala Nyeri & 1,93 & 2 & $0-4$ & 1,158 \\
\hline
\end{tabular}

Pada tabel 2 dapat dilihat bahwa skala kecemasan dan skala nyeri yang dirasakan oleh responden pada kelompok intervensi menunjukkan rerata nilai yang lebih rendah dibandingkan dengan kelompok kontrol. Rerata kecemasan responden pada kelompok intervensi menunjukkan nilai 0,93 sedangkan pada kelompok kontrol mencapai 1,43. Pada kelompok intervensi, rerata kecemasan responden mencapai 0,73 sedangkan pada kelompok kontrol rerata kecemasan anak mencapai 1,93.

c. Analisis Pengaruh Aromaterapi terhadap Skala Nyeri dan Kecemasan Anak Sekolah saat Mendapatkan Imunisasi Td pada

\section{Kelompok Intervensi dan Kontrol}

Tabel 3. Perbedaan Rerata Skala Nyeri dan Skala Kecemasan Anak pada Kelompok Intervensi dan Kontrol saat tindakan Imunisasi Td Tahun 2019

\begin{tabular}{llllll}
\hline Variabel & Kelompok & $\mathbf{n}$ & Mean & $\begin{array}{l}\text { Mean } \\
\text { Rank }\end{array}$ & $\begin{array}{l}\text { P. } \\
\text { Value }\end{array}$ \\
\hline $\begin{array}{l}\text { Skala } \\
\text { Kecemasan }\end{array}$ & Intervensi & 15 & 0,93 & 12,77 & 0,122 \\
& Kontrol & 14 & 1,43 & 17,39 & 0,122 \\
\hline Skala Nyeri & Intervensi & 15 & 0,73 & 10,93 & 0,005 \\
& Kontrol & 14 & 1,93 & 19,36 & 0,005 \\
\hline
\end{tabular}

Berdasarkan tabel 3 dapat dilihat bahwa $p$ value antara kedua kelompok pada variabel kecemasan menunjukkan nilai 0,122 yang berarti nilai ini >0,05 (a) yang berarti bahwa Ho diterima, sehingga tidak ada pengaruh penggunaan aromaterapi terhadap kecemasan anak SD saat dilakukan tindakan imunisasi Td. Pada variabel skala nyeri responden, menunjukkan nilai $p$-value yang lebih kecil dari a $(0,05)$, yaitu 0,005 yang berarti bahwa $\mathrm{Ho}$ ditolak dan Ha diterima. Hal ini berarti ada pengaruh penggunaan aromaterapi lavender terhadap nyeri yang dirasakan siswa SD saat tindakan injeksi imunisasi Td.

\section{PEMBAHASAN}

Pemberian imunisasi atau vaksin merupakan salah satu upaya yang dapat dilakukan untuk meminimalisir terjadinya penyakit pada anakanak, termasuk anak usia sekolah (CDC, 2016). Namun, upaya yang dilaksanakan secara periodik ini sering kali menjadi salah satu hal yang menakutkan bagi anak-anak karena diketahui dapat menimbulkan rasa sakit sehingga anak cenderung merasa cemas. Salah satu jenis imunisasi yang didapatkan anak-anak sekolah adalah Imunisasi Td untuk mencegah Dipteri dan Tetanus. Berdasarkan penelitian ini rerata anakanak yang mendapatkan imunisasi Td berada pada rentang usia 10-11 tahun atau dengan rerata usia 10,14 tahun yang sedang duduk di bangku kelas 5 sekolah dasar (SD). Hal ini sesuai dengan Peraturan Menteri Kesehatan Republik Indonesia No.7 Tahun 2012 bahwa target anak yang mendapatkan imunisasi Td adalah anak yang duduk di kelas 1, 2 dan 5 SD. Namun pada penelitian Sundoro, Bachtiar, \& Sari (2014) diungkapkan bahwa rerata usia anak yang mendapatkan imunisasi Td adalah 8,65 tahun dengan rentang usia anak dari 7-13 tahun. Jika dilihat dari sebaran jenis kelamin, antara anak laki-laki dan perempuan yang mendapatkan imunisasi perbandingannya 14:15, dimana hal ini tidak menunjukkan selisih yang terlalu jauh dan pelaksanaan imunisasi tidak mengenal perbedaan gender, dan terbukti efisien dalam menjangkau banyak anak maupun remaja (McMurtry et al., 2015). 
Rerata skala nyeri yang dirasakan anak pada kelompok kontrol setelah dilakukan imunisasi adalah 1,93, sedangkan pada kelompok intervensi, post-test skala nyeri menunjukkan rerata mencapai 0,73 yang berarti lebih rendah daripada post-test rerata skala nyeri pada kelompok kontrol. Nyeri yang dirasakan anak, sebagai akibat dari tindakan imunisasi yang didapat. Hockenberry, Wilson, \& Rodgers, (2016) juga menegaskan bahwa nyeri pada anak dapat dirasakan sebagai akibat dari luka, penyakit, ataupun prosedur medis, seperti misalnya tindakan injeksi. Nyeri merupakan pengalaman somatik yang tidak menyenangkan yang dikaitkan dengan adanya kerusakan jaringan aktual atau potensial dengan komponen sensorik, emosional, kognitif dan sosial (Williams \& Craig, 2016), termasuk nyeri yang dirasakan oleh anak, dimana nyeri yang dirasakan bersifat subyektif dan multidimensi (Hockenberry \& Wilson, 2009).

Rerata skala kecemasan yang dirasakan oleh anak-anak pada kelompok kontrol setelah dilakukan tindakan imunisasi mencapai 1,43, sedangkan pada kelompok intevensi nilai rerata kecemasan mencapai 1,43. Kecemasan yang dirasakan anak saat dilakukan imunisasi muncul karena takut terhadap rasa sakit atau nyeri yang akan dialami saat disuntik. Nyeri terhadap suntikan yang juga menyebabkan munculnya ketakutan pada anak telah diketahui menjadi kekhawatiran bagi anak sekolah saat harus menjalani imunisasi di sekolah (Bucci, MacDonald, Sondagar, \& Taddio, 2017). Taddio et al (2012) juga mengungkapkan dalam penelitiannya bahwa sebanyak $63 \%$ anak mengungkapkan ketakutannya terhadap jarum suntik, salah satunya saat akan dilakukan imunisasi. Hal ini juga sejalan dengan Taddio et al (2015) yang menjelaskan bahwa anak usia sekolah cenderung mengalami distres saat dilakukan imunisasi dan berdampak pada penghindaran tenaga kesehatan sehingga tindakan imunisasi menjadi terhambat. McMurtry et al. (2015) juga mengungkapkan hal yang senada, dimana anak sekolah cenderung merasa khawatir dengan rasa sakit yang akan dialami saat diimunisasi karena telah memiliki pengalaman sakit sebelumnya, dan hal ini dapat meningkatkan risiko terjadinya pingsan pada anak. Pengalaman negatif terhadap jarum suntik dapat menyebabkan keraguan untuk menjalani imunisasi dan penolakan terhadap imunisasi di masa mendatang baik untuk anak sekolah saat ini maupun anak-anak lainnya nanti karena kecemasan terhadap jarum suntik dan sikap negatif terhadap imunisasi dapat diturunkan dari generasi ke generasi (McMurtry et al., 2015; Taddio et al., 2012).

Pengalaman negatif dari imunisasi, seperti pengalaman rasa sakit dan ketakutan merupakan askep penting yang seharusnya dapat dimanipulasi untuk dapat mengoptimalkan pengalaman anak sekolah selama prosedur akut dan mempertahankan keberlanjutan imunisasi jangka panjang (Taddio, 2019). Berbagai tindakan nonfarmakologi untuk mengurangi nyeri direkomendasikan agar anak tidak merasa takut atau trauma. Implementasi tindakan manajemen nyeri ini juga sebagai bentuk penerapan atraumatic care pada anak (Hockenberry, Wilson, \& Rodgers, 2016). Pada penelitian ini penerapan atraumatic care dilakukan dengan pemberian aromaterapi lavender saat anak dilakukan imunisasi. Hasil penelitian ini menunjukkan bahwa $p$-value dari pengaruh aromaterapi lavender terhadap kecemasan anak adalah 0,122 $(>0,05)$ yang berarti tidak ada pengaruh pemberian aromaterapi lavender terhadap kecemasan yang dirasakan anak sekolah saat dilakukan imunisasi. Namun, jika dilihat dari perbedaan rerata, rerata kecemasan anak pada kelompok kontrol lebih tinggi dari kelompok kontrol. Hal yang senada juga terlihat pada penelitian Yayla, \& Ozdemir (2019) yang mengungkapkan bahwa penggunaan aromaterapi lavender tidak menunjukkan hasil yang signifikan dalam menurunkan kecemasan pasien yang akan mendapatkan tindakan invasif pemasangan central venous port catheter. Namun, Seyyed-Rasooli, Salehi, Mohammadpoorasl, Goljaryan, Seyyedi \& Thomson (2016) menyatakan bahwa penggunaan aromaterapi lavender yang dicampurkan dengan aroma lainnya seperti almond dan mawar menunjukkan penurunan yang signifikan pada kecemasan pasien dengan luka bakar termasuk juga menurunkan rasa nyeri.

Penggunaan aromaterapi diyakini diyakini memiliki efek anti mikroba, efek pengawet, efek antistres, efek anti-depresi, efek antiinflamasi, efek relaksasi, efek peningkatan imunitas tubuh serta memiliki efek menurunkan nyeri kronis (Lee, Lim, Song, Kim, \& Hur, 2017). Hal ini senada dengan hasil dari penelitian ini yang menunjukkan bahwa ada pengaruh menghirup aromaterapi lavender terhadap penurunan skala nyeri pasien anak saat dilakukan tindakan imunisasi dengan $p$-value $0,005(<0,05)$. Vaziri et al. (2019) juga mengungkapkan bahwa penggunaan aromaterapi lavender terhadap nyeri pada bayi saat mendapatkan vaksinasi terbukti efektif dalam menurunkan skala nyeri bayi yang terlihat dari durasi menangis bayi yang lebih singkat dibandingkan dengan kelompok kontrol. Penggunaan aromaterapi lavender juga terbukti efektif dalam menurunkan skala nyeri yang dirasakan anak usia pra sekolah saat dilakukan tindakan invasif pemasangan infus di Rumah Sakit dan direkomendasikan menjadi salah satu pilihan untuk mengatasi nyeri anak (Bikmoradi et al., 2017). Hal ini tidak terlepas dari reaksi kimiawi yang terjadi saat aroma dari minyak esensial terhirup. Ketika aroma dari minyak esensial yang berasal dari ekstrak tanaman terhirup, maka sel reseptor dari saraf 
olfaktorius akan terstimulasi dan impuls-impuls akan ditransmisikan ke pusat emosional otak dan sistem limbik. Terjadinya pencampuran impuls-impuls yang ditrasnmisikan tersebut menyebabkan terjadinya pengeluaran zat kimia internal tubuh, termasuk enkephalin dan endorfin, yang dapat mengurangi nyeri dan kecemasan, dan juga menurunkan level dari epinefrin dan norepinefrin. Dengan demikian, aromaterapi tersebut dapat bermanfaat untuk mengurangi agitasi, neuroleptik, kecemasan dan nyeri (Dehkordi, Baharanchi, \& Bekhradi, 2014).

\section{KESIMPULAN}

Intervensi inhalasi aromaterapi telah terbukti efektif untuk mengurangi nyeri anak sekolah saat dilakukan imunisasi, namun tidak terlihat perbedaan yang signifikan terhadap kecemasan anak saat dilakukan imunisasi. Namun, berdasarkan rerata kecemasan, dapat terlihat bahwa kecemasan yang dirasakan oleh anak-anak kelompok intervensi lebih rendah dibandingkan kelompok kontrol. Hal ini tidak terlepas dari efek aromaterapi lavender yang dapat merangsang pengeluaran hormon endorfin dan menurunkan hormon epinefrin.

\section{SARAN}

Perawat anak yang bertugas di puskesmas diharapkan dapat menerapkan intervensi inhalasi aromaterapi lavender kepada siswa saat dilakukan imunisasi sehingga anak dapat lebih mengontrol nyeri yang dirasakan sebagai bentuk penerapan atraumatic care.

\section{DAFTAR PUSTAKA}

Abbaszadeh, R., Tabari, F., Taherian, K., \& Torabi, S. (2017). Lavender Aromatherapy in Pain Management: A Review Study.

Bikmoradi, A., Harorani, M., Roshanaei, G., Moradkhani, S., \& Falahinia, G. H. (2016). The effect of inhalation aromatherapy with damask rose (Rosa damascena) essence on the pain intensity after dressing in patients with burns: A clinical randomized trial. Iranian journal of nursing and midwifery research, 21(3), 247.

Bikmoradi, A., Khaleghverdi, M., Seddighi, I., Moradkhani, S., Soltanian, A., \& Cheraghi, F. (2017). Effect of inhalation aromatherapy with lavender essence on pain associated with intravenous catheter insertion in preschool children: A quasi-experimental study. Complementary Therapies in Clinical Practice, 28, 85-91. doi:10.1016/j.ctcp.2017.05.008

Bikmoradi, A., Zafari, A., Oshvandi, K., Mazdeh, M., \&Roshanaei, G. (2014). Effect of progressive muscle relaxation on severity of pain in patients with multiple sclerosis: a randomized controlled trial. Hayat; 20 (1): $26-37$

Bucci, L. M., MacDonald, N. E., Sondagar, C., \& Taddio, A. (2017). Taking the sting out of school-based immunizations. Paediatrics \& Child Health, 22(1), 41-42.

Burns-Nader, S., Atencio, S., \& Chavez, M. (2016). Computer tablet distraction in children receiving an injection. Pain Medicine, 17(3), 590-595.

Cerne, D., Sannino, L., \& Petean, M. (2015). A randomised controlled trial examining the effectiveness of cartoons as a distraction technique. Nursing Children and Young People, 27(3), 28-33. doi:10.7748/ncyp.27.3.28.e534

Ciftci, E. K., Ozdemir, F. K., \& Aydın, D. (2016). Effect of flick application on pain level and duration of crying during infant vaccination. Italian journal of pediatrics, 42(1), 1-6.

Dehkordi, Z. R, Baharanchi, F. S. H, \& Bekhradi, R. (2014). Effect of lavender inhalation on the symptoms of primary dysmenorrhea and the amount of menstrual bleeding: A randomized clinical trial. Complementary Therapies in Medicine, 22(2), 212-219. 10.1016/j.ctim.2013.12.011

Giordano, C.N., Nelson, j., Kohen, L.L., Nijhawan, R., \& Srivastava, D. (2015). Local anesthesia: Evidence, Strategies, and Safety. Curr. Derm. Rep. ; 4 (3) :97-104 
Halpert, C., Meier, S., \& Naus, M. (2015). Reducing immunization injection pain in infants. BCMJ, 57, 189.

Hockenberry, M. J. \& Wilson D. (2009). Wong's essentials of pediatric nursing ( $7^{\text {th }}$ ed.). St. Louis: Mosby Elsevier Hockenberry, M. J, Wilson, D., \& Rodgers, C.C. (2016). Wong's Essentials Of Pediatric Nursing (10th ed.). Elsevier Health Science

Lakhan, S. E., Sheafer, H., \& Tepper, D. (2016). The effectiveness of aromatherapy in reducing pain: a systematic review and meta-analysis. Pain research and treatment, 2016.

Lee, M., Lim, S., Song, J., Kim, M., \& Hur, M. (2017). The effects of aromatherapy essential oil inhalation on stress, sleep quality and immunity in healthy adults: Randomized controlled trial. European Journal of Integrative Medicine, 12, 79-86. 10.1016/j.eujim.2017.04.009

McMurtry, C. M., Riddell, R. P., Taddio, A., Racine, N., Asmundson, G. J., Noel, M., ... \& Shah, V. (2015). Far from" just a poke": Common painful needle procedures and the development of needle fear. The Clinical journal of pain.

Nursalam. (2016). Metodologi Penelitian IImu Keperawatan: Pendekatan Praktis. Ed. 4. Jakarta: Salemba Medika

Taddio, A., Ipp, M., Thivakaran, S., Jamal, A., Parikh, C., Smart, S., . . Katz, J. (2012). Survey of the prevalence of immunization non-compliance due to needle fears in children and adults. Vaccine, 30(32), 4807-4812. doi:10.1016/j.vaccine.2012.05.011

Taddio, A., McMurtry, C. M., Shah, V., Riddell, R. P., Chambers, C. T., Noel, M., ... \& Lang, E. (2015). Reducing pain during vaccine injections: clinical practice guideline. Cmaj, 187(13), 975-982.

Taddio, A. (2019). Pain Pain Go Away: Improving the vaccination experience at school. Paediatrics \& Child Health, 24(S1). doi: 10.1093/pch/pxz016

Treede, R. D. (2018). The International Association for the Study of Pain definition of pain: as valid in 2018 as in 1979 , but in need of regularly updated footnotes. Pain reports, 3(2).

Şahiner, N. C., Inal, S., \& Akbay, A. S. (2015). The effect of combined stimulation of external cold and vibration during immunization on pain and anxiety levels in children. Journal of perianesthesia nursing, 30(3), 228-235.

Seyyed-Rasooli, A., Salehi, F., Mohammadpoorasl, A., Goljaryan, S., Seyyedi, Z., \& Thomson, B. (2016). Comparing the effects of aromatherapy massage and inhalation aromatherapy on anxiety and pain in burn patients: $A$ single-blind randomized clinical trial. Burns, 42(8), 1774-1780.

Stevens, K. E., \& Marvicsin, D. J. (2016). Evidence-Based Recommendations For Reducing Pediatric Distress During Vaccination. Pediatric nursing, 42(6).

Victoria, N. C., \& Murphy, A. Z. (2016). Exposure to early life pain: long term consequences and contributing mechanisms. Current opinion in behavioral sciences, 7, 61-68.

Yayla, E. M., \& Ozdemir, L. (2019). Effect of inhalation aromatherapy on procedural pain and anxiety after needle insertion into an implantable central venous port catheter: a quasi-randomized controlled pilot study. Cancer nursing, 42(1), 35-41. 